\title{
Nonmetallic Inclusions and Acicular Ferrite in Arc Welds of Pipeline Steels
}

\author{
Alexander A. Kazakov ${ }^{1}$, Daria Lyubochko ${ }^{1}$ \\ 1. St. Petersburg State Polytechnical University/Metallurgical Technologies Department, St. Petersburg, \\ Russian Federation
}

The purpose of this work is to study the influence of nonmetallic inclusions on structure formation of acicular ferrite in longitudinal submerged arc welds using light optical microscopy, scanning and transmission electron microscopy, and X-ray microanalysis.

Acicular ferrite is a desirable structure in welded pipeline steels, because it provides an optimal combination of both high strength and good toughness due to the fine "basket-weave" microstructure.

The weld metal of the samples investigated has a structure of acicular ferrite both in the center and at the periphery up to the point of the weld-fusion line (Fig.1). Acicular ferrite forms in consequence of the rapid cooling of steel from the austenitic state, when formation of allotriomorphic, Widmanstätten and massive ferrites are suppressed. Acicular ferrite plates are formed on ultrafine nucleation centers based on titanium oxides evolved during the deoxidation processes. Particles of MnS, namely Mn-depleted zones formed around the particles, may also be sites for acicular ferrite nucleation. To ensure the formation of titanium oxides, the amount of aluminum added to the metal should be minimal $(\leq 0,005 \%)$, because of its strong affinity for oxygen. Boron segregates to austenite grain boundaries and reduces grain boundary energy and the driving force for ferrite transformation in solid solution. It inhibits the formation of grain boundary ferrite and promotes the formation of intragranular acicular ferrite [1].

There were nonmetallic inclusions of different sizes inside the weld metal of all investigated specimens. The quantity of nonmetallic inclusions (Fig. 2a) varies from tens to hundreds for different samples, and depends on the explored place in the weld (inside weld, outside weld, central fusion zone). The composition of the inclusions corresponds to two major multi-component systems: $\mathrm{Al}_{2} \mathrm{O}_{3}-\mathrm{CaO}_{-} \mathrm{SiO}_{2-}$ $\mathrm{MnO}-\mathrm{Ti}_{\mathrm{x}} \mathrm{O}_{\mathrm{y}}$ and $\mathrm{Al}_{2} \mathrm{O}_{3}-\mathrm{CaO}-\mathrm{SiO}_{2}-\mathrm{MnO}-\mathrm{MgO}-\mathrm{Ti}_{\mathrm{x}} \mathrm{O}_{\mathrm{y}}-\mathrm{MnS}$ (Fig. 2b). The ultrafine nonmetallic inclusions create conditions for acicular ferrite formation in a weld. The presence of those kinds of inclusions is caused by technological modes of welding, and also wire and flux composition for welding. These inclusions may serve as substrates for formation of an acicular ferritic structure in weld metal [2]. It provides an optimum combination of strength and plastic properties of weld metal. Moreover, this structure and technology ensures achievement of full strength welds, because the curve of microhardness changes monotonically over the cross section of the welded joint, including the heat-affected zone. Data for the size and composition of nonmetallic inclusions are confirmed by studies carried out by transmission microscopy (Fig. 2c).

The study of the nature and distribution of nonmetallic inclusions in a cross section of a welded joint makes it possible to estimate their contribution to the structure formation in the joint. With knowledge of the thermal and physico-chemical characteristics of nonmetallic inclusions formation it becomes possible to correct welding technology in such a way as to obtain the desired weldment microstructure. 
References:

[1] D.S. Sarma et al., ISIJ International, 49 (2009), p.1063.

[2] M.V. Karasev et al., Welding and Diagnostics, 6 (2014), p. 45.

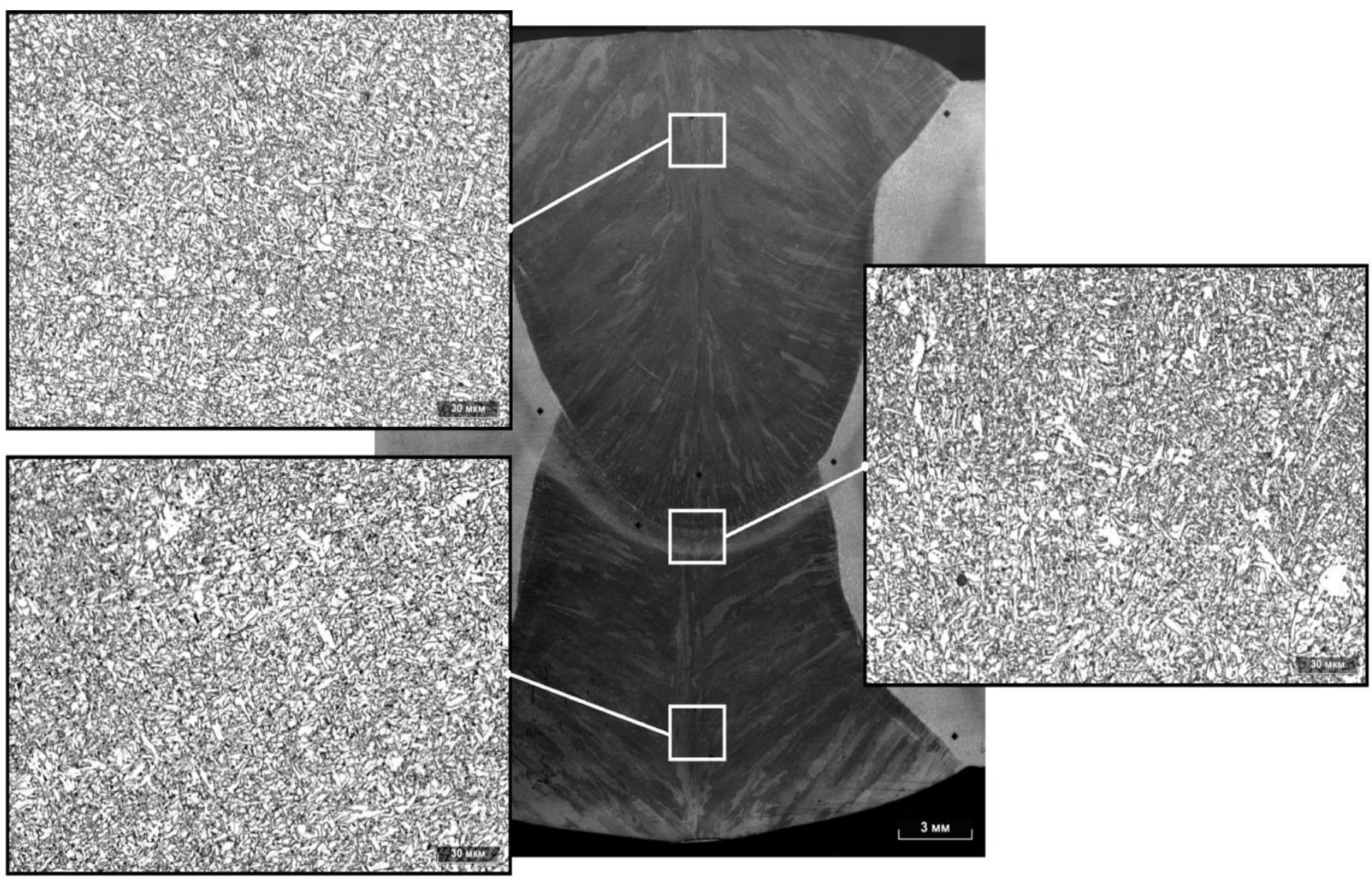

Figure 1. Panoramic image of the weld joint, $\times 50, \times 1000$

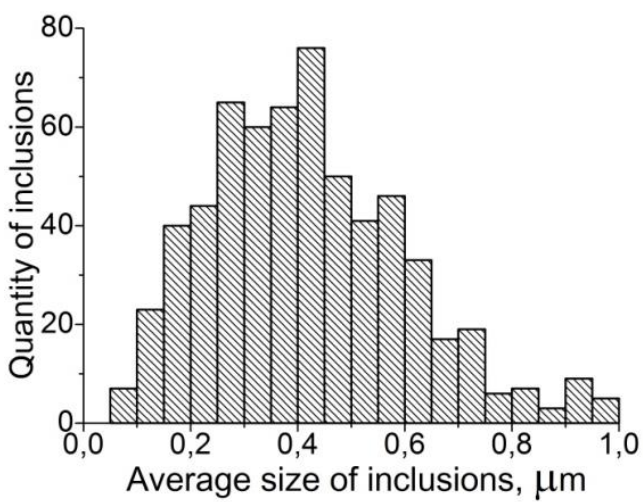

a)

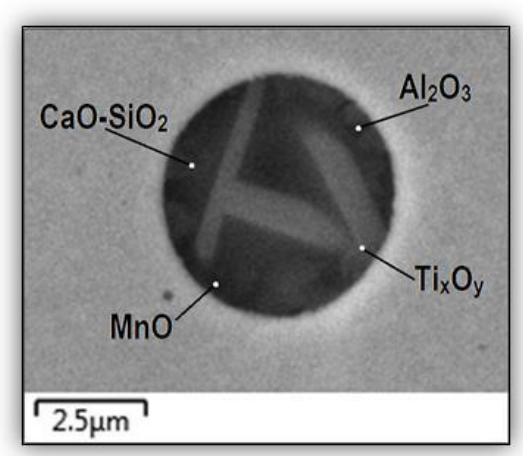

b)

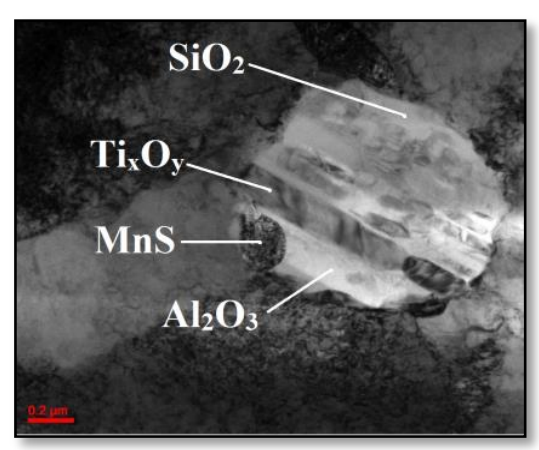

c)

Figure 2. a) The distribution of inclusions by size; b) and c) typical inclusion, found in the weld: (b) scanning electron microscopy; (c) transmission electron microscopy images 